\title{
Immediate and Long-Term Clinical and Angiographic Results from Wikfor Stent Treatment for True Bifurcation Narrowings
}

\author{
Angelo Anzuini, MD, Carlo Briguori, MD, PhD, Salvatore Rosanio, MD, PhD, \\ Monica Tocchi, MD, PhD, Paolo Pagnotta, MD, Hans Bonnier, MD, Giorgio Gimelli, MD, \\ Flavio Airoldi, MD, Alberto Margonato, MD, Victor Legrand, MD, PhD, and \\ Antonio Colombo, MD
}

From January 1996 to December 1998, 90 consecutive patients with true bifurcation lesions underwent percutaneous coronary angioplasty with Wiktor stent implantation in our centers. In 1 group (group $I, n=45$ ), a simple approach (main vessel stenting and balloon angioplasty of the side branch) was pursued. In the other group (group II, $n=45$ ), both the main vessel and the side branch were stented (" $T$ " technique). There was no significant difference in clinical and angiographic characteristics between the 2 groups. Angiographic and procedural successes were $100 \%$ and $95.6 \%$, respectively, in both groups. Angiographic results for the side branch were better in group II than in group I. In-hospital and long-term (12 month) major cardiac events were similar

T rue bifurcation lesions occur in $2 \%$ to $16 \%$ of stenoses being considered for percutaneous coronary intervention. Even if treatment of coronary bifurcation lesions is no longer a technical challenge, ${ }^{1-7}$ this area is still in search of a solution able to lower the incidence of long-term events. Indeed, the available long-term results report an incidence of restenosis up to $36 \%$, indicating that stenting a bifurcation leads to a higher risk of restenosis than stenting a lesion not involving a bifurcation. ${ }^{8-12}$ In addition, the frequent use of target lesion revascularization (TLR) as an end point for long-term success may miss restenosis of the side branch, which can be clinically silent.

\section{METHODS}

Study patients: This was a prospective nonrandomized study including all 90 consecutive patients with true bifurcation lesions (with the criteria specified below), who underwent percutaneous transluminal coronary angioplasty (PTCA) with Wiktor stent implantation from January 1996 to December 1998 in 3 participating centers. A true bifurcation lesion was

\footnotetext{
From Vita e Salute University, San Raffaele Hospital, Milan, Italy; Hôpital Cardiologique Universitaire, Liege, Belgium and Department of Cardiology, Catharina Hospital, Eindhoven, The Netherlands. Manuscript received May 25, 2001 ; revised manuscript received and accepted July 23, 2001

Address for reprints: Angelo Anzuini, MD, San Raffaele Hospital Via Olgettina 60, I-20132, Milan, Italy. E-mail: anzangelo@ yahoo.com
}

in the 2 groups. Target lesion revascularization was $15.5 \%$ in group I and $35.5 \%$ in group II $(p=0.12)$. In the main vessel, restenosis rate was $12.5 \%$ in group I and $25 \%$ in group II $(p=0.15)$. In the side branch, restenosis rate was $37.5 \%$ in group II and $12.5 \%$ in group I $(p=$ $<0.05$; odds ratio $2.42 ; 95 \%$ confidence interval 1.05 to 6.26). Event-free probability at 12 months was $61 \%$ in group II and $80 \%$ in group I $(p=0.10)$. When dealing with true bifurcation lesions, a simple strategy is associated with a lower risk of restenosis in the side branch. In contrast, a complex approach does not appear to give any benefit in terms of early or long-term outcome or restenosis rate. (C) 2001 by Excerpta Medica, Inc.

(Am J Cardiol 2001;88:1246-1250)

defined as a lesion inducing a narrowing of $\geq 50 \%$ in vessel diameter involving both the main vessel and the side branch. True bifurcation lesions involving a side branch with a reference diameter of $<2.5 \mathrm{~mm}$ were excluded from the study. All patients gave written, informed consent for the procedure. In addition, at the time of the initial stent implantation, patients were informed of the need for an angiography at 6 months and also a late (12 months) clinical follow-up.

Interventional procedure: Premedication consisted of $325 \mathrm{mg} /$ day of nonenteric coated oral aspirin, and ticlopidine $250 \mathrm{mg}$ twice daily beginning at least 2 days before the procedure. A bolus dose of 10,000 $\mathrm{U}$ of heparin was administered after sheath insertion, with repeat bolus given as needed to maintain an activated clotting time of approximately 300 seconds. Patients received intracoronary isosorbide dinitrate ( 0.1 to $0.3 \mathrm{mg}$ ) before initial and final angiograms to achieve maximal vasodilatation. All patients underwent PTCA by the standard technique via the femoral approach using an 8 Fr guiding catheter. After placement of the guiding catheter, 2 wires were introduced in the distal bed of the 2 branches. After sequential inflation of a semicompliant balloon in each branch (using a balloon-to-artery ratio of 1.0), the choice to employ a stent in only the main vessel or both vessels was left to the discretion of the operator. In 1 group (group I), a simple approach was undertaken, i.e, stenting of the main vessel followed by balloon angioplasty of the side branch through the struts of the 
TABLE 1 Baseline Clinical Characteristics of the Groups According to Treatment Strategy (single vs double stent)

\begin{tabular}{|lccc|}
\hline & $\begin{array}{c}\text { Single Stent } \\
(\mathrm{n}=45)\end{array}$ & $\begin{array}{c}\text { Double Stent } \\
(\mathrm{n}=45)\end{array}$ & $\mathrm{p}$ Value \\
\hline Age (yrs) & $59 \pm 10$ & $62 \pm 7$ & 0.10 \\
Men/women & $37 / 8$ & $31 / 14$ & 0.14 \\
Previous myocardial infarction & $21(46.7 \%)$ & $14(31.1 \%)$ & 0.13 \\
Left ventricular ejection fraction (\%) & $62 \pm 12$ & $62 \pm 10$ & 0.59 \\
Previous bypass surgery & $4(8.9 \%)$ & $4(8.9 \%)$ & 1.00 \\
Family history of coronary artery disease & $20(44.4 \%)$ & $16(35.6 \%)$ & 0.39 \\
Systemic hypertension & $13(28.9 \%)$ & $13(28.9 \%)$ & 1.00 \\
Diabetes mellitus & $10(22.2 \%)$ & $13(29.9 \%)$ & 0.38 \\
Unstable angina pectoris & $8(17.8)$ & $8(17.8 \%)$ & 1.00 \\
Hypercholesterolemia (>200 mg/dl) & $14(31.1 \%)$ & $20(44.4 \%)$ & 0.20 \\
Smoking & $18(40 \%)$ & $20(44.4 \%)$ & 0.67 \\
No. of coronary artery narrowed $>50 \%$ & & & 0.58 \\
1 & $25(55.5 \%)$ & $26(57.8 \%)$ & \\
2 & $7(15.5 \%)$ & $7(15.5 \%)$ & \\
3 & $13(29 \%)$ & $12(26.7 \%)$ & \\
\hline
\end{tabular}

TABLE 2 Angiographic Characteristics of the Lesions According to Treatment Strategy (single vs double stent)

\begin{tabular}{|c|c|c|c|}
\hline & $\begin{array}{l}\text { Single Stent } \\
(\mathrm{n}=45)\end{array}$ & $\begin{array}{l}\text { Double Stent } \\
(\mathrm{n}=45)\end{array}$ & p Value \\
\hline Coronary artery & & & 0.10 \\
\hline LAD diagonal & $24(53.3 \%)$ & $30(66.7 \%)$ & \\
\hline LC obtuse marginal & $17(37.8 \%)$ & $8(17.8 \%)$ & \\
\hline Right PDA & $4(8.9 \%)$ & $7(15.6 \%)$ & \\
\hline Lesion types* & & & 0.16 \\
\hline A & $12(7.2 \%)$ & $9(6.0 \%)$ & 0.44 \\
\hline B1 & $63(37.2 \%)$ & $44(29.5 \%)$ & 0.09 \\
\hline B2 & $78(46.1 \%)$ & $76(51 \%)$ & 0.30 \\
\hline C & $16(9.5 \%)$ & $20(13.4 \%)$ & 0.17 \\
\hline Thrombus & 0 & $4(2.8 \%)$ & 0.83 \\
\hline Calcific deposits & $11(24.4 \%)$ & $9(20.0 \%)$ & 0.61 \\
\hline \multicolumn{4}{|c|}{ Quantitative angiography } \\
\hline \multicolumn{4}{|c|}{ Vessel size $(\mathrm{mm})$} \\
\hline Main vessel & $3.38 \pm 0.20$ & $3.46 \pm 0.23$ & 0.10 \\
\hline Side branch & $2.73 \pm 0.27$ & $2.71 \pm 0.17$ & 0.66 \\
\hline \multicolumn{4}{|c|}{ Minimal lumen diameter $(\mathrm{mm})$} \\
\hline \multicolumn{4}{|c|}{ Main vessel } \\
\hline Before & $0.98 \pm 0.33$ & $1.07 \pm 0.17$ & 0.06 \\
\hline After & $2.81 \pm 0.28$ & $2.97 \pm 0.28$ & 0.58 \\
\hline Follow-up & $2.10 \pm 0.51$ & $2.02 \pm 0.51$ & 0.19 \\
\hline \multicolumn{4}{|l|}{ Side branch } \\
\hline Before & $0.84 \pm 0.13$ & $0.86 \pm 0.12$ & 0.46 \\
\hline After & $1.94 \pm 0.17$ & $2.36 \pm 0.18$ & $<0.001$ \\
\hline Follow-up & $1.53 \pm 0.35$ & $1.44 \pm 0.40$ & 0.30 \\
\hline Lesion length $(\mathrm{mm})$ & $14 \pm 2$ & $15 \pm 3$ & 0.40 \\
\hline \multicolumn{4}{|l|}{ Percent stenosis (\%) } \\
\hline \multicolumn{4}{|l|}{ Main vessel } \\
\hline Before & $71 \pm 10$ & $69 \pm 5$ & 0.29 \\
\hline After & $17 \pm 6$ & $14 \pm 3$ & $<0.001$ \\
\hline Follow-up & $39 \pm 13$ & $42 \pm 15$ & 0.12 \\
\hline \multicolumn{4}{|l|}{ Side branch } \\
\hline Before & $68 \pm 6$ & $68 \pm 5$ & 0.91 \\
\hline After & $29 \pm 4$ & $13 \pm 5$ & $<0.001$ \\
\hline Follow-up & $44 \pm 11$ & $47 \pm 13$ & 0.20 \\
\hline
\end{tabular}

delivering and deploying the other stent in the major vessel (the vertical segment of the T). Finally, a kissing balloon inflation was performed to optimize the acute result. ${ }^{2}$ A Wiktor stent (Medtronic Interventional Vascular, Kerkrade, The Netherlands) was used in all patients; this was a premounted balloon-expandable stent composed of a single, loose, interdigitating, coil-like tantalum wire $(0.125$ $\mathrm{mm}$ in diameter) formed into a sinusoidal wave and configured as a helix. The crimped stent profile is $1.5 \mathrm{~mm}$ and deployment does not induce any modification in stent length (14 to 16 $\mathrm{mm}$ ). After deployment performed at 9 atm, stent expansion was completed with an additional inflation to a maximum of 14 atm, until a good angiographic result was obtained.

Postprocedural medication protocol: Heparin was discontinued after the procedure. Ticlopidine $250 \mathrm{mg}$ twice daily was continued for 1 month together with aspirin $325 \mathrm{mg} /$ day, which was continued long-term.

Angiographic measurements were performed with an automated computer-based system (QCA-CMS version 3.0, MEDIS, Leiden, The Netherlands). Lesions were characterized according to the modified American College of Cardiology/American Heart Association classification. ${ }^{13}$ Angiographic success was assessed off-line by a quantitative estimate of the residual stenosis $<30 \%$ of the lumen diameter within the stent, effectively positioned at the intended site and by the gradation of the anterograde flow as a Thrombolysis In Myocardial Infarction flow 3 in both the parent vessel and side branch. Procedural success was defined as the achievement of angiographic success in the absence of any in-hospital major adverse cardiac events (i.e., Q-wave or non-Q-wave myocardial infarction, bypass surgery, PTCA, and death).

Postprocedure management and follow-up: After a successful procedure, sheaths were removed in 4 to 6 hours. Follow-up was performed in all patients by an interview or a telephone conversation with the patient.

stent. In the other group (group II), both the main vessel and the side branch were treated with stent implantation. The side branch lesion was always stented using the " $\mathrm{T}$ " technique. In particular, T stenting was performed by deploying the first stent in the side branch (the horizontal segment of the T), then
Non-Q-wave myocardial infarction was defined as an elevation in total creatine kinase equal or greater than twice the normal value without development of any new pathologic $Q$ wave. Clinical follow-up was obtained at 6 months in all patients. Angiographic follow-up was planned for all patients at 6 months or 
earlier if there was a clinical indication. Restenosis was defined as $\geq 50 \%$ diameter stenosis of the treated lesion. TLR was defined as any repeat percutaneous intervention to the target lesion (parent or side branch) or any coronary bypass graft to the treated vessel during follow-up.

Statistical analysis: Continuous variables are presented as mean $\pm 1 \mathrm{SD}$. Differences between groups were assessed by chi-square analysis for categorical variables and Student's $t$ test for continuous variables. The contribution of all clinical, angiographic, and procedural variables to the early and late outcome was evaluated with multivariate logistic regression analysis. Event-free survival curves were calculated using the Kaplan-Meier method; differences between groups were tested with the log-rank test statistic. Probability values $<0.05$ were considered significant. Data were analyzed with SPSS 10 for Windows (SPSS Inc., Chicago, Illinois).

\section{RESULTS}

Clinical characteristics (Table 1): There was no significant difference in clinical characteristics between the 2 groups.

Angiographic and procedural characteristics (Table 2): There were no differences in the treatment strategies in the 3 centers (group $\mathrm{I}=52.6 \%, 51.6 \%$, and $47.4 \%$; group II $=47.4 \%, 48.4 \%$, and $53.4 \%$, respectively; $\mathrm{p}=0.93$ ). There was a trend toward a larger minimal lumen diameter of the main vessel in group II. Angiographic and procedural success was $100 \%$ and $95.6 \%$, respectively, in both groups. The procedure for group II needed more stents $(2.3 \pm 0.5$ vs 1.2 $\pm 0.4, \mathrm{p}=0.004)$ and took more time $(115 \pm 52 \mathrm{vs}$ $98 \pm 45$ minutes, $\mathrm{p}<0.05)$ than it did for group I. Final balloon/artery ratio was similar in the 2 groups in the parent vessel $(1.06 \pm 0.04$ in group I vs $1.07 \pm$ 0.05 in group II, $p=0.27$ ), but was different in the side branch $(1.03 \pm 0.05$ in group I vs $1.10 \pm 0.05$ in group II, $\mathrm{p}<0.05)$. Maximal inflation pressure applied in the 2 groups was similar in the parent vessel $(12 \pm$ 1 in group I vs $12 \pm 0.5$ in group II, p $=0.77$ ) but different in the side branch $(10 \pm 0.5$ in group I vs 12 \pm 1 in group II, $p<0.05$ ). Final kissing balloon inflation was performed in all group II patients and in $<40 \%$ in group I $(\mathrm{p}<0.05)$. Final minimal lumen diameter of the side branch was larger in group II. Furthermore, residual diameter stenosis in both the main vessel and side branch was greater in group I.

In-hospital and long-term outcome: In-hospital major adverse cardiac events were similar in the 2 groups. No patient in the 2 groups experienced death and/or urgent repeat PTCA or bypass surgery. NonQ-wave myocardial infarction occurred in 2 patients (4.4\%) in both groups I and II. At 12 months, the occurrence of death, bypass surgery, and acute myocardial infarction was similar in the 2 groups. TLR rate was $15.6 \%$ in group I and $35.6 \%$ in group II $(\mathrm{p}=$ 0.12). All patients with TLR had eventual repeat PTCA at the main vessel, side branch, or both. $\mathrm{Cu}-$ mulative event-free survival in the 2 groups is shown in Figure 1: There was a trend toward a worse late

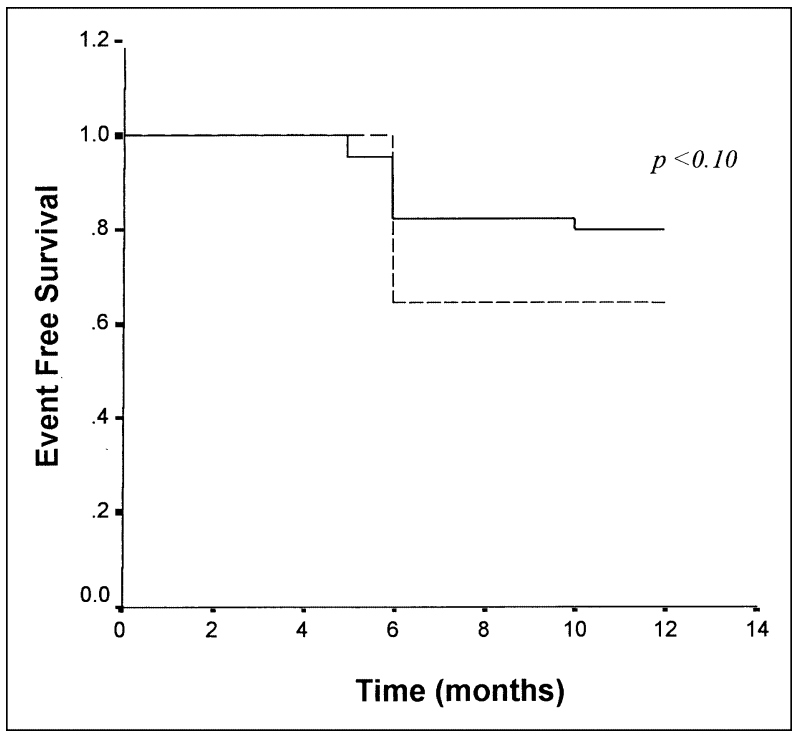

FIGURE 1. Restenosis rate in the main vessel and in the side branch according to the treatment strategy. Group I (solid line), 1 stent (only in the main vessel) and balloon angioplasty in the side branch; group II (broken line), 2 stents (both main vessel and side branch).

outcome in group 2 than in group 1 (event-free probability at 12 months, $61 \%$ vs $80 \%$; $\mathrm{p}=0.10)$.

Angiographic follow-up (Table 3) was performed in 40 patients $(90 \%)$ in both groups at $8 \pm 2$ months (range 3 to 12). There was a trend toward an increase in restenosis in group II in the main branch $(12.5 \%$ in group I and $25 \%$ in group II; $p=0.15$; odds ratio [OR] 2.33; 95\% confidence interval [CI] 0.72 to 7.59 ) and a statistically significant difference in the side branch $(37.5 \%$ in group II and $12.5 \%$ in group I; $p=$ $<0.05$; OR 2.42; 95\% CI 1.05 to 6.26) (Table 3, Figure 2). Restenosis rate in at least 1 of the 2 vessels treated was $26.7 \%$ in group I and $37.8 \%$ in group II (p $=0.25 ;$ OR $2.36 ; 95 \%$ CI 1.67 to 4.08 ). Combined restenosis of the parent vessel and side branch was $27.5 \%$ in group I and $42.5 \%$ in group II $(\mathrm{p}=0.16$; OR 2.33 ; $95 \%$ CI 0.72 to 7.59 ).

\section{DISCUSSION}

The main results of our study are that (1) stenting of bifurcation lesions can be achieved with a high success rate and an acceptable complication rate, and (2) stenting of both limbs of bifurcation lesions offers no advantage (in term of angiographic and clinical outcome) over stenting of 1 arm and balloon angioplasty of the other vessel. Treatment of complex bifurcation lesions remains a challenge, even with the help of stents. In fact, use of a stent has virtually abolished in-hospital complications, but overall, the 1 -year major adverse cardiac event is still $31 \%$, almost twice the incidence observed for stenting 1 "BENESTENT" (Belgium and Netherlands STENT Study)-like lesion. These findings suggest a key role for anatomic factors in the clinical outcome of coronary angioplasty. Not only vessel diameter or lesion 


\begin{tabular}{|c|c|c|c|}
\hline & $\begin{array}{l}\text { Single Stent } \\
(\mathrm{n}=45)\end{array}$ & $\begin{array}{l}\text { Double Stent } \\
(\mathrm{n}=45)\end{array}$ & $\mathrm{p}$ Value \\
\hline \multicolumn{4}{|l|}{ Main vessel } \\
\hline Gain & $1.82 \pm 0.51$ & $1.90 \pm 0.34$ & 0.48 \\
\hline Late loss & $0.72 \pm 0.44$ & $0.94 \pm 0.55$ & 0.05 \\
\hline Loss index & $0.41 \pm 0.26$ & $0.47 \pm 0.22$ & 0.27 \\
\hline \multicolumn{4}{|l|}{ Side branch } \\
\hline Gain & $1.09 \pm 0.25$ & $1.50 \pm 0.22$ & $<0.001$ \\
\hline Late loss & $0.40 \pm 0.30$ & $0.91 \pm 0.39$ & $<0.001$ \\
\hline Loss index & $0.39 \pm 0.32$ & $0.61 \pm 0.27$ & 0.001 \\
\hline \multicolumn{4}{|l|}{ In hospital MACE } \\
\hline Myocardial infarction & $2(4.4 \%)$ & $2(4.4 \%)$ & 1.00 \\
\hline Coronary bypass & 0 & 0 & \\
\hline Death & 0 & 0 & \\
\hline \multicolumn{4}{|l|}{ Follow-up MACE } \\
\hline Myocardial infarction & 0 & 0 & 1.00 \\
\hline Coronary bypass & 0 & $1(2.2 \%)$ & 0.31 \\
\hline Death & 0 & 0 & 1.00 \\
\hline \multicolumn{4}{|c|}{ Target lesion revascularization } \\
\hline Global & 7 (15.6\%) & $16(35.6 \%)$ & 0.12 \\
\hline Main vessel & $5(11.1 \%)$ & $10(22.2 \%)$ & \\
\hline Side branch & $5(11.1 \%)$ & $14(31.1 \%)$ & \\
\hline Both & $3(6.7 \%)$ & $8(17.8 \%)$ & \\
\hline \multicolumn{4}{|l|}{ Restenosis rate } \\
\hline Global & $11 / 40(27.5 \%)$ & $17 / 40(42.5 \%)$ & 0.16 \\
\hline Main vessels & $4 / 40(10 \%)$ & $10 / 40(25 \%)$ & \\
\hline Side branch & $7 / 40(17.5 \%)$ & $15 / 40(37.5 \%)$ & \\
\hline Both & $2 / 40(5 \%)$ & $8 / 40(20 \%)$ & \\
\hline
\end{tabular}

ter" concept does not seem to be valid for the side branch, i.e., a generally small vessel. The mechanisms of such an unfavorable outcome for small vessels are not well understood. Factors proposed are (1) high degree of vessel stretch and injury, and (2) high metal density. An acceptable result with only 1 stent in the major vessel and no severe residual stenosis in the side branch not only is more cost effective, but also offers a similar clinical outcome.

Previous studies: Our results are in agreement with recent studies. $^{8-12}$ Pan et $\mathrm{al}^{8}$ reported that complex strategies (i.e., deployment of 1 stent at the ostium of the side branch and complete reconstruction of the entire bifurcation with additional implantation of 1 or 2 stents at the parent vessel) appear to provide no advantages over the simpler strategy of deploying just 1 stent in the parent vessel covering the takeoff of the side branch followed by ostial side branch balloon dilation across the stent's struts. Yamashita et $\mathrm{al}^{10}$ reported that a complex strategy (group B) provided no advantage in

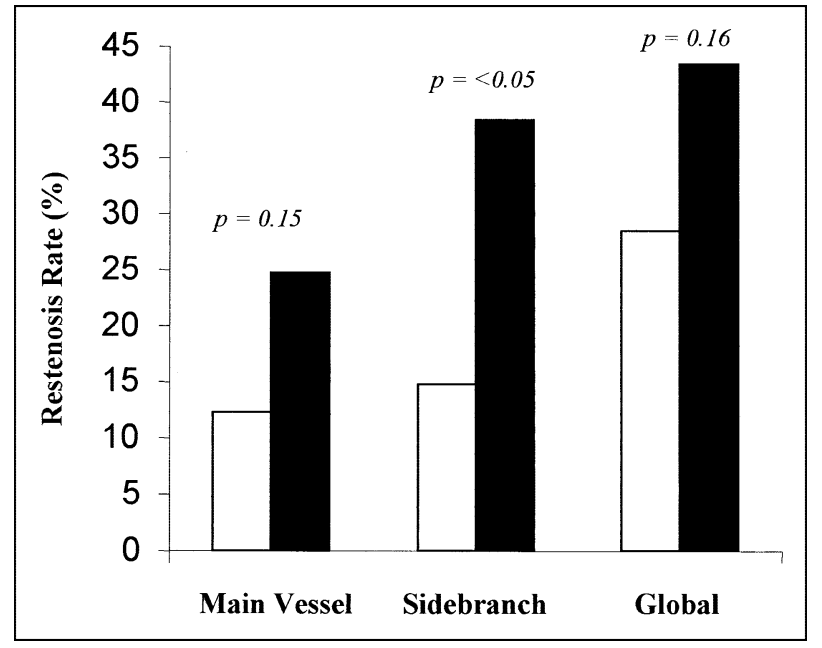

FIGURE 2. Event-free survival in the $\mathbf{2}$ groups. Group I (white bars), 1 stent (only in the main vessel), and balloon angioplasty on the side branch; group II (black bars), 2 stents (both main vessel and side branch).

length, but also complex anatomy, such as bifurcations, are related to the likelihood of late events, notably restenosis.

We failed to demonstrated any significant benefit of the kissing stents $\mathrm{T}$ technique. Although this approach provides better scaffolding and the best opening of both sides of the bifurcation, such an aggressive approach is hampered by an higher intimal proliferation that obviates the initial gain. The "bigger is bet- terms of procedural success and late outcome versus a simpler strategy (group P). Stent placement on both branches resulted in a lower residual stenosis (group B $7.4 \pm 10.9 \%$ vs group P $23.4 \% \pm 18.7 \% ; \mathrm{p}<0.001$ ) in the side branch. In-hospital major adverse cardiac events occurred only in group B $(13 \%$ vs $0 \%, p$ $<0.05)$. At 6 months, the angiographic restenosis rate (group B 56\% vs group P 52\%), TLR (37\% vs 30\%, respectively) and the incidence of total major adverse cardiac events were similar. Accordingly, Al Suwaidi et $\mathrm{al}^{12}$ found no significant differences at 1 year in survival or the occurrence of myocardial infarction, coronary artery bypass surgery, or need for repeat revascularization between complex versus simple strategy. Patients who had stent deployment in both arteries had more severe angina and required revascularization more often than those who underwent stent deployment in 1 arm only. Furthermore, there was a trend toward better long-term outcome in patients with stent implantation in only $1 \mathrm{arm}$.

Study limitations: It may be difficult to assess the degree of residual stenosis with angiography after Wiktor stent implantation because of its high radiopacity and possible plaque prolapse. Therefore, there may be an overestimation of the final lumen dimension in the stented segments. Practice of systematic angiographic follow-up can induce a higher rate of reintervention. However, in all cases, the decision to perform reintervention was based on (1) clinical status including stress test (when available), and (2) angiographic severity of restenosis $(\geq 50 \%)$. 
Acknowledgment: We thank Maurizio Alessandrini, RN, and Davide Maccagni, RN, for their technical support.

1. Meier B, Gruentzig AR, King SB III, Douglas JS Jr, Hollman J, Ischinger T, Aueron F, Galan K. Risk of side branch occlusion during coronary angioplasty. Am J Cardiol 1984;53:10-14.

2. Colombo A, Gaglione A, Nakamura S, Finci L. "Kissing" stents for bifurcational coronary lesion. Cathet Cardiovasc Diagn 1993;30:327-330.

3. Schampaert E, Fort S, Adelman AG, Schwartz L. The V-stent: a nove technique for coronary bifurcation stenting. Cathet Cardiovasc Diagn 1996;39: $320-326$.

4. Dauerman H, Higgins PJ, Sparano AM, Gibson CM, Garber GR, Carrozza JP Jr, Kuntz RE, Laham RJ, Shubrooks SJ Jr, Baim DS, Cohen DJ. Mechanical debulking versus balloon angioplasty for the treatment of true bifurcation lesions. $J$ Am Coll Cardiol 1998;32:1845-1852.

5. Chevalier B, Glatt B, Royer T, Guyon P. Placement of coronary stents in bifurcation lesions by the "culotte" technique. Am J Cardiol 1998;82:943-949.

6. Lefèvre T, Louvard Y, Morice MC, Dumas P, Loubeyre C, Benslimane A Premchand RK, Guillard N, Piechaud JF. Stenting of bifurcation lesions: classification, treatments, and results. Cathet Cardiovasc Intervent 2000;49:274-283.

7. Kobayashi Y, Colombo A, Akiyama T, Reimers B, Martini G, Di Mario C. Modified "T" stenting: a technique for kissing stents in bifurcational coronary lesions. Cathet Cardiovasc Diagn 1998;43:323-326.
8. Pan M, Suarez de Lezo J, Medina A, Romero M, Hernandez E, Segura P, Castroviejo JR, Pavlovic D, Malian F, Ramirez A, Castillo JC. Simple and complex stent strategies for bifurcated coronary arterial stenosis involving the side branch origin. Am J Cardiol 1998;83:1320-1325.

9. Sheiban I, Albiero R, Marsico F, Dharmadhikari A, Tzifos V, Pagnotta P, Montorfano M, Leonardo F, Saba P, Di Mario C, Colombo A. Immediate and long-term results of "T" stenting for bifurcation coronary lesions. Am J Cardiol 2000;85:1141-1144.

10. Yamashita T, Nishida T, Adamian MG, Briguori C, Finci L, Di Mario C, Tobis JM, Colombo A. Bifurcation lesions: two stents versus one stent-immediate and follow-up results. J Am Coll Cardiol 2000;35:1145-1151.

11. Carrie D, Elbaz M, Dambrin G, Saint-Cricq F, Dugrand P, Fourcade J, Puel J. Coronary stenting of bifurcation lesions using " $T$ " of "reverse $Y$ " configuration with Wiktor stent. Am J Cardiol 1998;82:1418-1421.

12. Al Suwaidi J, Berger PB, Rihal CS, Garratt KN, Bell MR, Ting HH, Bresnahan JF, Grill DE, Holmes DR Jr. Immediate and long-term outcome of intracoronary stent implantation for true bifurcation lesions. J Am Coll Cardiol 2000;35:929-936

13. Ryan TJ, Faxon DP, Gunnar RM, Kennedy JW, King SB III, Loop F, Peterson KL, Reeves TJ, Williams DO, Winters WL Jr. Guidelines for percutaneous transluminal coronary angioplasty: a report of the American College of Cardiology/American Heart Association Task Force on assessment of diagnostic and therapeutic cardiovascular procedures. Circulation 1988; 78:486-502. 